\title{
An experiment in progress
}

\author{
Singapore's current investment in science is remarkably strong, but it isn't yet clear if the resulting knowledge and \\ innovation will go on to fuel economic growth, as the country expects.
}

$\mathbf{F}_{\mathrm{n}}^{\circ}$ or many Singaporean scientists, the word 'recession' must not mean much. Whereas countries such as Spain, which seriously invested in research over the past few years, have been forced to cut back sharply on science spending because of the economic meltdown, Singapore's investment keeps growing unabated. Many scientifically developed countries have found it challenging to meet the target of spending $2.5 \%$ of their gross domestic product (GDP) on research and development (R\&D). Meanwhile, Singapore's 2006-2010 Science \& Technology Plan called for 3\%, growing from 2.3\% in 2005. In absolute terms, given the fast growth of Singapore's economy (with a predicted growth rate of $\sim 13-15 \%$ in 2010 ), the actual amount spent in $\mathrm{R} \& \mathrm{D}$ will grow from $S \$ 6.5$ billion ( $\sim 4.5$ billion) in 2005 to $\$ \$ 13.5$ billion ( $\sim 10$ billion) in 2010 .

Money, however, is only the first part of the story. Singapore has also had a clear vision on deciding how to spend it. In broad terms, the country has invested in three fronts: infrastructure, creating bricks-and-mortar, world-class research hubs such as Biopolis; human capital, attracting an international cadre of seasoned researchers to the country and spending millions of dollars for nearly 1,000 Singaporeans to train at the top universities around the world before returning to the country; and intellectual property, focusing on driving basic research toward commercial application.

Singapore's small size and relatively short history have protected it from developing the clunky administrative structures that can delay bold decision making. For example, in June 2006 the government decided to make translational and clinical research the focus of its next scientific-development phase. To work, the idea required stakeholders from universities, the Ministry of Trade and Industry, the Ministry of Health and other organizations to agree on a strategic plan. Whereas this process would have taken months, perhaps years, almost anywhere else, it took less than two days for the working group to meet and agree on the way forward, which is already in place.

The last ingredient in Singapore's unusual scientific recipe is stability. In most countries, governments come and go, as do their commitments to R\&D. Singapore's government has been very stable, making it possible to make and stick to very long-term scientific plans, a situation unknown to researchers in most other countries.

So, everything seems to be in place for Singapore to emerge as a scientific powerhouse, and there are some early indications that the investment is paying off. For instance, the cumulative number of peer-reviewed papers in all disciplines authored by Singaporean scientists rose from 1,202 in 2007 to over 2,600 in 2009. Similarly, the number of awarded patents has more than doubled from 138 in
2006 to 305 in 2008, spinning off several start-up companies, 21 of which were active as of July 2009.

Yet, in spite of these accomplishments, it would be premature to proclaim Singapore's success. In fact, some of Singapore's strengths may become liabilities as it consolidates its emerging position. First, until 2005, over $90 \%$ of the funds available for research went to the Ministry of Trade and Industry, the mandate of which is economic growth and job creation. Although it is understandable that a small country needs to look for ways to maximize its return on investment, such a strong focus on economic output may come at the expense of basic research, the value of which cannot be measured in immediate returns. Seeking to avoid this pitfall, the 2006-2010 Science \& Technology Plan has diversified the science investment portfolio with the creation of the National Research Foundation, which funds investigator-led basic science and which garnered $36 \%$ of the budget.

Second, as its pushes translational research, the country has quickly realized that its size makes it impractical to launch an all-encompassing research program. Singapore has therefore decided to focus on five disease areas: gastric cancer, eye disease, schizophrenia, metabolic disease and dengue fever. Singapore's interest in these conditions stems partly from their high incidence among its inhabitants-a mixture of people of Chinese, Indian and Malay ethnic backgrounds. This has led many Singaporean researchers to focus their work on what they call the "Asian phenotype"-a concept that highlights the relevance of their work to Singapore's interests but needs to be defined more rigorously in scientific terms. It is of interest to study potential biological differences between Asians and, say, people of European descent that may account for susceptibility to certain diseases. But the idea of a common Asian phenotype for such a heterogeneous population might be too simplistic to be so entrenched in Singapore's scientific culture. Singaporean researchers shouldn't overlook this fact as they try to make their work appealing to funding bodies.

Last, failure is the name of the game in translational research-most drug-development programs fail, and a lot of the investment in biomedicine does not yield economic returns. So, Singapore's ambitious translational programs may well fail. Privately, some native and foreign scientists express concerns that the Singaporean culture has little tolerance for (or maybe even fear of) failure. It is therefore uncertain how Singapore will react to the natural process of attrition in translational research and the consequences it may have on future spending priorities. For the time being, though, Singaporean scientists should not lose sleep over this matter-the 2011-2015 Science \& Technology Plan has reportedly set its proposed expenditure in R\&D at $3.5 \%$ of the country's GDP. 